\section{A emergência do gesto de apontar na Síndrome de Down em contexto clínico}

The emergence of the gesture of pointing in Down syndrome in clinical context

Ediclécia Sousa de MELO (UFPB) clecia_kesinha@hotmail.com

Ivonaldo Leidson Barbosa LIMA (UFPB) ivonaldoleidson@gmail.com

Paulo Vinícius ÁVILA-NÓBREGA (UEPB) pvletras@gmail.com

Recebido em: 30 de jan. de 2019. Aceito em: 12 de jun. de 2019.

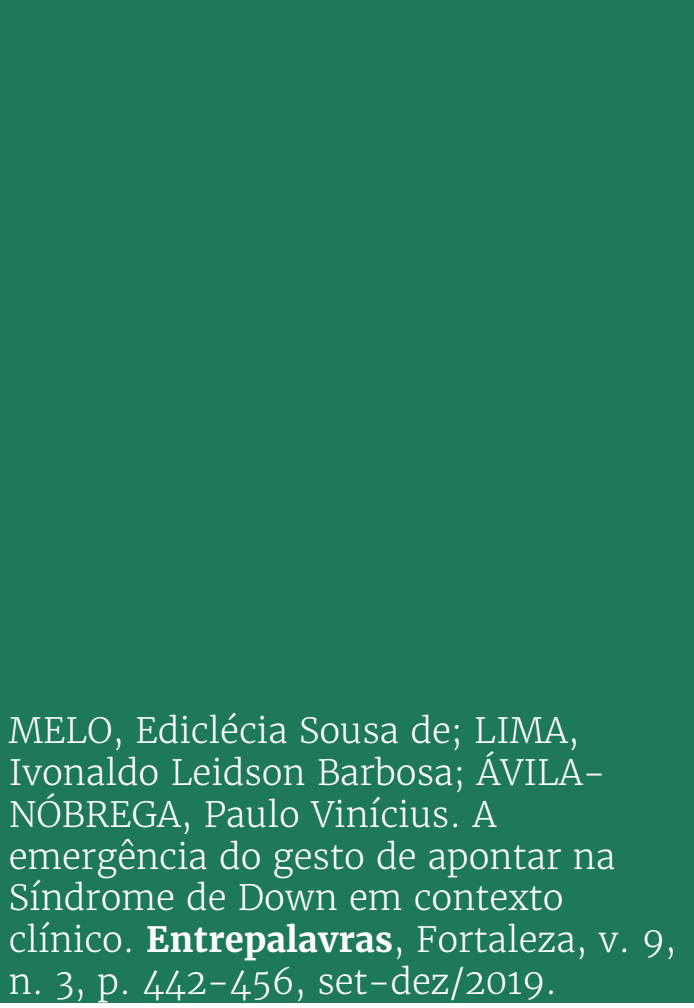

Resumo: A síndrome de Down (SD) é uma condição genética que provoca uma série de alterações no desenvolvimento linguístico da criança. Em relação à linguagem, é importante considerar sua natureza multimodal, assumindo-a como um envelope linguístico (ÁVILANÓBREGA, 2018) constituído de gestos, fala e olhar. Desse modo, é fundamental observar como o envelope linguístico multimodal emerge e é mobilizado pela criança com SD, em diferentes contextos. Este trabalho teve o objetivo de analisar a emergência do gesto do apontar de crianças com SD, em contextos de atendimento clínico. O estudo foi desenvolvido na Clínica Escola de Fonoaudiologia de uma instituição de ensino superior da Paraíba, a partir do registro de atendimentos terapêuticos fonoaudiológicos de duas díades: estagiária e criança com SD. Os dados foram registrados qualitativamente no programa ELAN - EUDICO Linguistic Annotator. Pode-se observar que o gesto de apontar emergiu com frequência no envelope linguístico multimodal das crianças, facilitando sua interação com as estagiárias, bem como na atenção conjunta e referência.

Palavras-chave: Síndrome de Down. Linguagem. Gesto de Apontar. 
Abstract: The Down syndrome (DS) is a genetic condition that causes several changes in the child's language development. About language, it is important to consider its multimodal nature, taking it as a linguistic envelope (ÁVILA-NÓBREGA, 2018) made up of gestures, speechs and looks. Thus, it is fundamental to observe how the multimodal linguistic envelope emerges and is mobilized by the child with DS in different contexts. This work had the objective of analyzing the emergence of gesture of pointing in children with DS in contexts of clinical care. This study was developed at the Clinical School of Speech, Language and Hearing Therapy of a higher education institution of Paraíba, based on the registry of the speech-language therapeutic care of two dyads: intern and child with DS. Data were registred qualitatively in the ELAN - EUDICO Linguistic Annotator program. It was observed that the gesture of pointing emerged frequently in the children's multimodal linguistic envelope, facilitating their interaction with the interns, as well as in the joint attention and reference.

Keywords: Down syndrome. Language. Pointing.

\section{Introdução}

A síndrome de Down (doravante, SD) é uma das cromossomopatias mais estudadas no mundo. Há alta incidência na população - cerca de 1 para cada 800 indivíduos nascidos vivos -, além disso, provoca múltiplas alterações congênitas, que podem gerar implicações no processo de desenvolvimento motor, neurofisiológico, cognitivo e linguístico.

Estudos como os de Freire et al. (2014) apontaram que a SD provoca alteração no desenvolvimento da linguagem das crianças, especialmente em relação à linguagem expressiva verbal, o que repercute na comunicação social. Segundo as autoras, as crianças com SD apresentam dificuldades no desenvolvimento de "habilidades de comunicação mais sofisticadas, embora sua compreensão para vocabulário, gramática e sintaxe seja usualmente maior do que a sua habilidade expressiva sugere" (p. 253).

Diante disso, o processo de aquisição da linguagem nesse grupo tem sido estudado na tentativa de favorecer o aperfeiçoamento de estratégias terapêuticas e escolares voltadas ao desenvolvimento linguístico infantil.

Uma perspectiva que deve ser considerada, nesse contexto, é a multimodalidade. McNeill (1985) expôs a premissa de que a linguagem é sempre multimodal, pois gesto e fala são constitutivos de um único sistema linguístico. O elemento "multimodal", para Hazel, Montensen e Rasmussen (2014), no processo de constituição da interação, se faz presente a partir da produção de ações, como o olhar, a fala, os gestos etc. 
v. 9 (3)

Nesse sentido, essa pluralidade de elementos se encontra integrada numa mesma matriz de produção e significação, sendo cruciais, então, para o processo de aquisição da linguagem e a estimulação nos contextos clínicos. Desse modo, esse estudo teve o objetivo de analisar a emergência do gesto do apontar de crianças com SD em contextos de atendimento clínico.

\section{A síndrome de Down em foco}

A SD é uma alteração genética caracterizada pela presença de 47 cromossomos em cada célula, ao invés de 46, e, em lugar de dois cromossomos 21 comuns, há três cromossomos 21 em cada célula, o que levou ao termo trissomia 21. Além da trissomia, há outras alterações cromossômicas em crianças com a mesma síndrome: a translocação e o mosaicismo.

A translocação ocorre em cerca de 3\% a 5\% das crianças com SD. Em crianças com essa variação, o número total de cromossomos nas células é 46, mas o cromossomo 21 extra está ligado a outro cromossomo, então, ocorre novamente um total de três cromossomos 21 presentes em cada célula. O que difere da trissomia é que o terceiro cromossomo 21 não é livre, mas está ligado, ou translocado a outro cromossomo, geralmente aos cromossomos 14, 21 ou 22. Todavia, o cromossomo 21 extra, ou parte dele, também poderia se aderir a outros cromossomos.

O terceiro tipo, e menos comum, de problemas cromossômicos em crianças com SD, segundo Pueschel (2002, p. 61), é o mosaicismo. Essa variação cromossômica geralmente ocorre em 1\% das crianças. O mosaicismo é considerado como resultado de um erro em uma das primeiras divisões celulares. Após o nascimento do bebê, encontram-se algumas células com 47 cromossomos e outras células com o número normal de 46. Vários estudiosos relatam que algumas crianças com mosaicismo apresentam traços menos acentuados de SD e que o seu desempenho intelectual é melhor do que a média para crianças com a trissomia 21.

Conforme os estudos de Pueschel (2002, p. 67), existem alguns fatores associados ao aumento do risco de ter um filho com SD, por exemplo: idade materna de 35 anos de idade ou mais; idade paterna de 45 anos ou mais; nascimento anterior de uma criança com SD na família, ou uma variação cromossômica; translocação balanceada em um dos pais; pais com desordens cromossômicas. 
A SD se apresenta da mesma forma independentemente do sexo da criança, podendo aparecer em qualquer família, mesmo que esta não tenha casos antecedentes de SD ou outra síndrome. Podemse ter pessoas com SD bastante diferentes entre si, no que se refere às características físicas e à presença de patologias, além das características provenientes da família que cada indivíduo pode apresentar. Ainda, a intensidade da deficiência intelectual, o atraso no desenvolvimento motor e a capacidade de adaptação na sociedade são bem particulares de cada sujeito. Apesar de o desenvolvimento neurológico, psicológico e físico da pessoa com SD sofrer influência genética, isso também será determinado pelas oportunidades que lhes serão oferecidas no decorrer da vida (DALLA DÉA; BALDIN; DALLA DÉA, 2009).

No que diz respeito ao atraso no desenvolvimento da linguagem, o menor reconhecimento das regras gramaticais e sintáticas da língua, bem como as dificuldades na produção da fala apresentadas por essas crianças, resultam na apresentação de um vocabulário mais reduzido, o que, frequentemente, faz com que elas não consigam se expressar na mesma medida em que compreendem o que é falado, levando-as a serem subestimadas em termos de desenvolvimento cognitivo. Essas mesmas alterações linguísticas poderão afetar o desenvolvimento de outras habilidades cognitivas, pois há maior dificuldade ao usar os recursos da linguagem para pensar, raciocinar e relembrar informações (LIMA; DELGADO; CAVALCANTE, 2017; ALVES; DELGADO; VASCONCELOS, 2008).

Embora, na literatura, sejam apresentadas essas dificuldades sociais e de aprendizagem do sujeito com SD, acreditamos que não há impedimentos para as suas habilidades dialógicas, pois, mesmo sendo um indivíduo com essa síndrome, ele tem condições de corresponder às iniciativas de engajamento que os parceiros promovam, quando são utilizados elementos gestuais, visuais e corporais, por exemplo.

A clínica de linguagem vem trazendo uma grande contribuição na estimulação precoce, e, cada vez mais, as famílias se mobilizam para lutar em prol de melhorias de vida para os sujeitos com Down. Além disso, as pesquisas recentes estão interessadas em descobrir novos rumos para o atendimento de sujeitos com SD e para a interação com eles em diversos contextos dialógicos (LIMA, DELGADO, CAVALCANTE, 2018; LIMA, 2016; LIMA, CAVALCANTE, 2015; ÁVILA-NÓBREGA, 2017).

Com as experiências que vimos adquirindo na Clínica Fonoaudiológica, e com o desempenho dos profissionais da linguagem que atendem as crianças e os adolescentes em contextos terapêuticos, 
v. 9 (3)

442-456 set-dez 2019

acreditamos que a SD não é requisito para inaptidões sociais, interacionais, educacionais e profissionais dos sujeitos com essa síndrome. O estímulo precoce na clínica e o acolhimento familiar vêm mostrando grande amadurecimento de questões sociocognitivas e linguísticas dos indivíduos atendidos.

Dando continuidade, discutimos na seção seguinte, o papel da atenção conjunta e da intencionalidade no atendimento da criança com SD.

\section{Atenção conjunta e intencionalidade na Aquisição da Linguagem}

Nesta seção, apresentamos um levantamento de estudos voltados à atenção conjunta (doravante, AC), para mostrar como acontecem as performances dialógicas de crianças com SD em atendimento clínico, pois acreditamos que é no lócus da $\mathrm{AC}$ onde acontecem as ações intencionais e a percepção do parceiro como um ser de intencionalidade também. Isso promove, na criança, a entrada no sistema da linguagem e a constitui como sujeito da interação, mesmo que não faça um uso considerável das produções morfossintáticas.

Para tanto, abordaremos os estudos que Tomasello (2003) e Tomasello et al. (2005) vêm desenvolvendo na Alemanha, na área da Psicologia, bem como algumas premissas desenvolvidas por Aquino e Salomão (2010), ao produzirem um estudo sobre AC e situação de nãoatenção conjunta com díade mãe-criança; e, por fim, discutiremos o trabalho de Állan e Souza (2011), que fazem um percurso pelos estudos de Tomasello.

A discussão a respeito da intencionalidade é bastante antiga e é enviesada por vicissitudes, principalmente do know-how da Psicologia Experimental e da Filosofia da Mente, que procuraram descrever os processos cognitivos e comportamentais relacionados ao que seria orgânico, natural ou consciente no estatuto do intencional.

O ponto de partida, segundo Soares (2008-2009, p. 191), foi a tese do filósofo alemão Franz Clemens Brentano, que revisitou, na tradição aristotélica e escolástica, o arcabouço da intencionalidade, no processo psíquico e físico. Nesse caminho filosófico, ainda se encontram contribuições de nomes, como, por exemplo, dos alemães Edmund Gustav Husserl e Martin Heidegger e do francês Maurice Merleau-Ponty. Algumas críticas são realizadas com relação a esse período, uma vez que os estudos eram muito debruçados no Behaviorismo e na Psicologia Experimental (MIGUENS, 2001, p. 38). 
Dando prosseguimento aos nossos achados, iniciaremos, então, explorando a literatura acerca de pesquisas que envolvem o direcionamento do olhar, uma vez que explicam um possível caminho para a intencionalidade e promovem os tipos de AC necessários nas cenas dialógicas.

Outros achados na área da Psicologia apontam que, nas primeiras redes de interações estabelecidas entre os bebês e os indivíduos adultos, há um complexo conjunto de habilidades que dão suporte ao desenvolvimento de potencialidades que são inerentes ao ser humano, como a capacidade de apreender significados pelo compartilhar de atividades culturalmente construídas, essenciais para o desenvolvimento de habilidades sociocognitivas que têm seu ponto de partida na infância (AQUINO; SALOMÃO, 2010, p. 107).

Segundo as autoras supracitadas nessa área, é investigado o momento no qual os bebês conseguem se comunicar de forma intencional, bem como interpretar um comportamento do adulto como intencional, o papel das primeiras interações entre mães e bebês no surgimento dessa habilidade, a potencial relação entre contextos de AC, a comunicação intencional e a aquisição da linguagem; e as contribuições de aspectos cognitivos, afetivos e motores, partes do desenvolvimento infantil, que podem estar diretamente relacionados à explicação da comunicação de natureza intencional.

Sendo assim, a intencionalidade é caracterizada como uma propriedade de certas habilidades cognitivas, de algumas espécies animais, de serem direcionadas para certos objetivos. A ação intencional é caracterizada como aquela direcionada para objetivos; a intenção é o planejamento de ações direcionadas para objetivos; os agentes intencionais são organismos animais que agem no mundo direcionados para objetivos; a atenção é a percepção direcionada para objetivos (objetos ou estados de coisas do mundo); e a intencionalidade compartilhada é o conjunto de interações colaborativas entre indivíduos humanos direcionadas para os mesmos objetivos (TOMASELLO et al., 2005, p. 677-680; ÁLLAN; SOUZA, 2011, p. 242).

Aquino e Salomão (2010, p. 108) postulam que a habilidade de comunicação intencional desenvolve-se por meio de trocas recíprocas, do espelhamento afetivo e da imitação mútua, os quais possibilitam ao bebê uma oportunidade única para estabelecer distinções entre o "eu" e a perspectiva do outro. Para as autoras, o desenvolvimento de ações intencionais nos bebês resultaria da maneira única e tipicamente 
v. 9 (3)

442-456 set-dez 2019

humana de comunicação recíproca e intencional entre os bebês e seus cuidadores, desde períodos iniciais da vida infantil. Além disso, a comunicação intencional nos bebês é uma habilidade coconstruída, num contexto social e relacional, desde as primeiras trocas sociais estabelecidas entre o bebê e o adulto.

Para Állan e Souza (2009, p. 165), a compreensão que a criança tem dos papéis específicos que ela, o adulto e o referencial externo desempenham dentro de quadros de AC lhe permite entender as intenções comunicativas do adulto, quando este utiliza símbolos linguísticos (palavra escrita ou falada) para manipular os estados intencionais da criança, uma vez que esta somente é capaz de compreender e utilizar símbolos linguísticos quando compreende que os adultos utilizam esses elementos intencionalmente, para atingir objetivos específicos. Sendo assim, a compreensão da intenção comunicativa é uma condição necessária para a aquisição da linguagem.

A seguir, discorreremos sobre a metodologia utilizada neste trabalho.

\section{Métodos}

O presente estudo foi originado no LAFE - Laboratório de Aquisição da Fala e da Escrita - da Universidade Federal da Paraíba (UFPB) e se caracteriza como uma pesquisa transversal e qualitativa. Em relação aos seus objetivos, como descritiva, pois ela foi voltada à descrição de características de determinada população ou fenômeno. Por fim, em relação aos procedimentos técnicos utilizados, como estudo de caso, pois existe o propósito, na pesquisa, de formular hipóteses e explicar variáveis a partir da descrição do contexto investigado (GIL, 2002).

A pesquisa foi desenvolvida na Clínica-Escola de Fonoaudiologia da UFPB, localizada no município de João Pessoa/ $\mathrm{PB}$, durante as ações do projeto de extensão "Letramento em pauta: intervenção fonoaudiológica em sujeitos com síndrome de Down".

Foram utilizados, neste artigo, registros de duas díades do referido projeto de extensão, constituídas cada uma por uma estagiária estudante de Fonoaudiologia e uma criança com SD. A linguagem de DUAS crianças com SD foi analisada e vale destacar que essas crianças são irmãs. A criança 1 (C1) é do sexo masculino e possuía dois anos de idade durante a coleta dos dados. A criança 2 (C2) também é do sexo masculino e possuía seis anos de idade durante a coleta. 
As sessões analisadas foram planejadas pelas estagiárias e supervisionadas por fonoaudiólogos. Os pesquisadores colocaram uma máquina filmadora dentro da sala, para registro de toda a interação da forma mais natural, no contexto pesquisado. Os vídeos foram transferidos para o programa ELAN (EUDICO Linguistic Annotator), ferramenta criada no Max Planck Institute for Psycholinguistics, Nijmegen - Holanda, que permite a transcrição e análise dos dados. Durante a análise dos vídeos, foram criadas três trilhas de observação para cada membro participante da filmagem: a fala, os gestos e o olhar.

Ressalte-se que, esse estudo obteve aprovação do Comitê de Ética em Pesquisa com Seres Humanos, do Centro de Ciências da Saúde da instituição de origem, sob o parecer de número 1.360.357.

\section{Análise dos dados}

$1^{a}$ análise C1 - Situação comunicativa - Quer dançar?

Contexto: Após interagir com $\mathrm{C} 1$ e com alguns brinquedos no chão, a estagiária 1 levanta para inserir o vídeo no computador e convida a criança para dançar na sala.

Quadro 1 - Fragmento de transcrição da primeira cena C1

\begin{tabular}{|c|c|c|c|}
\hline $\begin{array}{c}\text { Tempo } \\
\text { inicial }\end{array}$ & $\begin{array}{c}\text { Tempo } \\
\text { final }\end{array}$ & $\begin{array}{c}\text { Trilha } \\
\text { multimodal }\end{array}$ & Produção multimodal \\
\hline 05:16 & $05: 18$ & P. oral E1 & Vamos cantar a musiquinha vamos? \\
\hline 05:16 & $05: 18$ & P. gestual E1 & Andando pela sala \\
\hline $05: 19$ & $05: 20$ & P. oral E1 & Tu quer dançar C1? \\
\hline 05:16 & $05: 21$ & P. gestual C1 & Senta no chão e pega brinquedos \\
\hline $05: 19$ & $05: 21$ & Olhar C1 & Observa os brinquedos \\
\hline $05: 19$ & $05: 21$ & P. oral E1 & Tu quer dançar, C1? \\
\hline $05: 22$ & $05: 24$ & P. oral E1 & Quer dançar? (perto do computador) \\
\hline $05: 24$ & $05: 26$ & P. oral E1 & Quer dançar? \\
\hline 05:24 & $05: 26$ & P. gestual C1 & Aponta para a E1 com objeto na mão \\
\hline
\end{tabular}

Legenda: P. = Produção; E1 = Estagiária 1; C1 = Criança 1

Fonte: Elaborado pelos autores.

A cena acima mostra o processo de construção do gesto de apontar pela criança e pela terapeuta. C1 é convidada a dançar por E1, porém desvia a atenção para os brinquedos que estão espalhados em cima do tapete. A criança utiliza o gesto de apontar com objeto direcionado à E1 no momento em que é questionada se quer participar da dança. 
V. 9 (3)

442-456 set-dez 2019

Segundo Cavalcante (2012), o gesto de apontar exerce uma posição de destaque em relação aos emblemas produzidos pela criança. Inicialmente, o apontar ocorre de forma desordenada, assim como os demais emblemas, mas, ao longo do tempo, vai se ajustando conforme as interações.

De acordo com Kendon (2004), o apontar pode ser realizado com distintas partes do corpo (a cabeça, a mão, o dedo, a face), e o que há em comum é a definição do movimento em forma de linha reta e a manutenção da posição por algum tempo endereçada ao alvo.

$2^{a}$ análise C1- Situação comunicativa 6 - Cadê o carro?

Contexto: A criança e E1 guardam brinquedos espalhados pelo chão. A terapeuta observa um carrinho entre os brinquedos e mostra à criança.

Quadro 2 - Fragmento de transcrição da segunda cena C1

\begin{tabular}{|c|c|c|c|}
\hline $\begin{array}{l}\text { Tempo } \\
\text { inicial }\end{array}$ & $\begin{array}{c}\text { Tempo } \\
\text { final }\end{array}$ & $\begin{array}{c}\text { Trilha } \\
\text { multimodal }\end{array}$ & Produção multimodal \\
\hline $05: 24$ & 05:29 & P. oral E1 & $\begin{array}{c}\text { Cadê o carro? Cadê o carro? Cadê o carro que } \\
\text { eu te dei? }\end{array}$ \\
\hline $05: 25$ & $05: 27$ & P. gestual E1 & $\begin{array}{c}\text { Aponta em direção ao centro da sala } \\
\text { (brinquedos) com o dedo indicador } \\
\text { (Apontar) }\end{array}$ \\
\hline $05: 25$ & $05: 27$ & Olhar E1 & Olha em direção ao centro da sala \\
\hline $05: 28$ & 05:29 & P. gestual C1 & $\begin{array}{l}\text { Aproxima-se mais da câmera, dá as costas } \\
\text { para a E1 }\end{array}$ \\
\hline $05: 26$ & $05: 29$ & P. oral C1 & Carru? \\
\hline $05: 29$ & 05:30 & P. gestual C1 & $\begin{array}{l}\text { Afastando-se da E1 e apontando para trás } \\
\text { com dedo polegar }\end{array}$ \\
\hline 05:29 & $05: 30$ & P. oral C1 & Taiu \\
\hline $05: 29$ & $05: 30$ & Olhar C1 & Olha para trás \\
\hline
\end{tabular}

Legenda: P. = Produção; E1 = Estagiária 1; C1 = Criança.

Fonte: Elaborado pelos autores.

Nessa situação comunicativa, observamos que a terapeuta questiona a criança acerca de um objeto que se encontra na sala, ao mesmo tempo em que aponta convencionalmente para os brinquedos. Em seguida, a criança se afasta da terapeuta e produz o enunciado "carru", andando e apontando para trás com o dedo polegar.

Nesse fragmento, constatamos que a criança produz um gesto de apontar para indicar a localização de um objeto no ambiente. Observamos que a criança participa e interage com as terapeutas em um 
processo de construção linguística que envolve gestos, olhar, prosódia e produção vocal, o que constitui a matriz multimodal em contextos de AC. Ressaltamos que o apontar é um gesto favorecedor para a comunicação entre a criança e a terapeuta.

Nas próximas sessões, observamos o processo de construção dos emblemas em $\mathrm{C} 2$, em cenas de atendimento fonoaudiológico, para que mais adiante possamos analisar e representar os resultados globais dos dois irmãos com SD.

$3^{a}$ análise $C_{2}-$ Situação comunicativa 2 - Cadê tua orelha?

Contexto: Após iniciar a atividade desenhando os olhos, C2 e E2 passam a desenhar as orelhas. Enquanto a terapeuta chama a atenção da criança para a atividade, o olhar é direcionado à caneta que se encontra com E2. E1 se mantém distanciada da câmera nessa cena de interação.

Quadro 3 - Fragmento de transcrição da primeira cena de C2

\begin{tabular}{|c|c|c|c|}
\hline $\begin{array}{c}\text { Tempo } \\
\text { inicial }\end{array}$ & $\begin{array}{c}\text { Tempo } \\
\text { final }\end{array}$ & $\begin{array}{c}\text { Trilha } \\
\text { multimodal }\end{array}$ & Produção multimodal \\
\hline 11:02 & $11: 04$ & P. oral E2 & Olha pra ali \\
\hline $11: 02$ & $11: 04$ & Olhar C2 & Vira e olha para a E2 \\
\hline $11: 03$ & $11: 04$ & P. oral E2 & Cadê tua orelha? \\
\hline $11: 03$ & $11: 05$ & P. gestual C2 & $\begin{array}{c}\text { Aponta para a sua bochecha, encosta bem o } \\
\text { dedo (Apontar) }\end{array}$ \\
\hline 11:03 & $11: 05$ & Olhar C2 & Olha para a E2 \\
\hline 11:03 & $11: 05$ & Ex. facial & Abre a boca \\
\hline 11:05 & $11: 07$ & P. oral E2 & A orelha, a orelha né aqui não \\
\hline 11:05 & $11: 07$ & P. gestual E2 & $\begin{array}{c}\text { Aponta para sua orelha encosta o dedo e } \\
\text { balança a cabeça - parece negar (Apontar) }\end{array}$ \\
\hline
\end{tabular}

Legenda: P. = Produção; E2 = Estagiária 2; C2 = Criança 2

Fonte: Elaborado pelos autores.

A cena mostra uma situação que ocorre em alguns momentos durante a atividade elaborada pelas terapeutas, pois a criança trocava a posição das partes do corpo ao ser questionada pelas estagiárias. Durante a cena interativa, observamos que a criança olha atentamente para a caneta, ao apontar, abre a boca, mas não produz som ou enunciado. 
V. 9 (3)

442-456 set-dez 2019

As terapeutas, antes de desenhar as partes do corpo de um menino no cartaz, perguntam à criança a respeito da localização da parte a ser representada e apontam para o objeto como indicação do local. Nessa cena, além do apontar convencional, utilizando o dedo indicador, a criança responde produzindo gestos dêiticos, ou seja, gestos demonstrativos ou direcionais (MCNEILL, 1992). Assim, a criança solicita algo estendendo o braço, e a terapeuta produz o emblema de negação balançando a cabeça para um lado e para o outro.

De acordo com Lima (2015), os gestos de apontar são produzidos pelas crianças com SD em contextos de interação e, com o passar do tempo, não desaparecem, pois a criança passa a produzir com mais intensidade esses dêiticos, combinando-os com outros modos de linguagem com maior frequência visando estabelecer a interação com o parceiro.

$4^{a}$ análise $C_{2}$ - Situação comunicativa 3 - Qual é a menina?

Contexto: Após pegar a criança que estava sentada na cama e colocá-la no chão, a terapeuta inicia uma atividade de colagem.

Quadro 4 - Fragmento de transcrição da segunda cena de C2

\begin{tabular}{|c|c|c|c|}
\hline $\begin{array}{c}\text { Tempo } \\
\text { inicial }\end{array}$ & $\begin{array}{c}\text { Tempo } \\
\text { final }\end{array}$ & $\begin{array}{c}\text { Trilha } \\
\text { multimodal }\end{array}$ & Produção multimodal \\
\hline 04:33 & $04: 35$ & P. oral E1 & Qual é a menina, é essa ou essa? \\
\hline 04:33 & $04: 35$ & Olhar E2 & Olha para o cartaz \\
\hline 04:33 & $04: 35$ & P. gestual E2 & $\begin{array}{c}\text { Aponta para um lado e para o outro tocando } \\
\text { no cartaz com as pontas dos dedos }\end{array}$ \\
\hline 04:33 & $04: 35$ & Olhar C2 & Observa o cartaz \\
\hline $04: 35$ & $04: 36$ & P. gestual C2 & $\begin{array}{c}\text { Aponta para as duas figuras com a mão } \\
\text { aberta utilizando a ponta dos dedos }\end{array}$ \\
\hline $04: 35$ & $04: 36$ & Olhar C2 & Olha para cada figura no cartaz \\
\hline $04: 36$ & $04: 38$ & P.oral E2 & é só um, diz pra mim qual é \\
\hline 04:36 & $04: 38$ & Olhar E2 & Olha para a criança \\
\hline $04: 36$ & $04: 38$ & P. gestual E2 & $\begin{array}{c}\text { Mostra o dedo indicador e movimenta-O se } \\
\text { referindo ao número 1 (emblema) }\end{array}$ \\
\hline 04:36 & $04: 38$ & Olhar C2 & Olha para E2 \\
\hline 04:40 & $04: 42$ & P. gestual C2 & $\begin{array}{c}\text { Aponta para as duas figuras com o dedo } \\
\text { indicador, e, em seguida, olha para E2 }\end{array}$ \\
\hline
\end{tabular}

Legenda: P. = Produção; E2 = Estagiária 2; C2 = Criança 2

Fonte: Elaborado pelos autores. 
Nessa situação comunicativa, notamos que a criança observa toda a ação da terapeuta. Mesmo observando atentamente, muitos dos questionamentos feitos por E1 não são respondidos adequadamente pela criança, como em "qual é a menina, é essa ou essa?", em que a terapeuta, de forma associada à pergunta, utiliza o recurso gestual dêitico, referenciando o objeto, mas, mesmo assim, a criança aponta para as duas figuras. Percebe-se uma dificuldade por parte da criança em distinguir o gênero masculino e o feminino nesse fragmento. A produção gestual da terapeuta é atrelada à produção vocal, em que uma não ocupa o lugar da outra, mas se complementam linguisticamente na cena interativa, uma vez que o gesto e a fala estão integrados em uma única matriz de significação (MCNEILL,1985).

A criança faz uso do apontar com a mão aberta tocando com a ponta do dedo indicador no objeto. Observamos que, em muitos momentos, a terapeuta aponta para o objeto, solicita que a criança mostre determinado espaço e, em seguida, esta aponta para o local solicitado. Percebemos que, geralmente, C2 recorta o gesto da terapeuta e utiliza o emblema de apontar como principal forma de interação associado ao olhar.

O gesto de apontar é um dos mais frequentes no envelope multimodal (ÁVILA-NÓBREGA, 2018) de crianças com SD, como apresentado por Lima (2016). Esse gesto se desenvolve a partir de comportamentos exploratórios da criança visando pegar, agarrar e mostrar os objetos para o outro (SCHAFFER, 1984).

Bates, O'Connell e Shore (1987) concebem o gesto de apontar como a essência da referência, ou seja, o apontar seria um ato por meio do qual o bebê destaca um determinado objeto no mundo e o oferece para que outra pessoa passe também a observá-lo, o que facilita, assim, a interação e, de acordo com Costa Filho (2011), o estabelecimento da AC, tornando-se essenciais para o desenvolvimento da linguagem.

Diante disso, a constituição do envelope multimodal pela criança, bem como sua emergência e seu uso em diferentes contextos, facilita a interação com o outro e favorece o processo de aquisição da linguagem na SD. Por isso, os gestos, junto a outros elementos multimodais, devem ser incentivados na prática da clínica fonoaudiológica, pelo importante papel que podem desempenhar na intervenção para as crianças com algum comprometimento de linguagem. 
v. 9 (3)

442-456 set-dez 2019

\section{Considerações finais}

Com este estudo, observamos que os gestos exercem um papel importante no processo de aquisição da linguagem de crianças com SD, visto que atuam e se aperfeiçoam de forma conjunta com a fala e o olhar na interação e produção de significado.

Ressalta-se que os dados analisados foram produzidos em um contexto linguístico muito particular, o ambiente clínico, que pode limitar as conclusões do estudo. Por isso, mais pesquisas sobre essa temática podem e devem ser realizadas.

Se analisarmos, especificamente, o gesto de apontar, verificaremos, pelas cenas analisadas, sua contribuição para a manutenção da atividade dialógica, para a referência e para a entrada em cenas de atenção conjunta - uma das bases, segundo Tomasello (2003), para a aquisição da linguagem.

Desse modo, o estudo do envelope linguístico multimodal de crianças com SD fomenta o trabalho de linguistas, educadores e fonoaudiólogos, fornecendo-os subsídios para uma atuação mais sensível às capacidades e especificidades desses sujeitos, além da promoção de reflexões acerca da importância da criação de ambientes interacionais (clínicos, familiares, educacionais) contextualizados, que mobilizam envelopes multimodais ricos e complexos dos interlocutores, não excludentes e que privilegiam determinados elementos.

\section{Referências}

ÁLLAN, S.; SOUZA, C.B.A. O Modelo de Tomasello sobre a Evolução CognitivoLinguística Humana. Psicologia: Teoria e Pesquisa. Vol. 25 n. 2, p. 161-168. Abr-Jun 2009.

ÁLLAN, S.; SOUZA, C.B.A. Intencionalidade em Tomasello, Searle, Dennett e em Abordagens Comportamentais da Cognição Humana. Psicologia: Teoria e Pesquisa. Vol. 27 n. 2, p. 241-248. Abr-Jun 2011.

ALVES, G.A.S.; DELGADO, I.C.; VASCONCELOS, M.L. O desenvolvimento da linguagem escrita por crianças com síndrome de Down. Revista Prolíngua. João Pessoa. Vol 1. N 1. p. 47-55, 2008.

AQUINO, F.S.B.; SALOMÃO, N.M.R. Intencionalidade comunicativa: teorias e implicações para a cognição social infantil. Estudos de Psicologia. Campinas, v.27, n.3, p. 413-420, 2010.

ÁVILA-NÓBREGA, P. V. O Sistema de Referenciação Multimodal de Crianças com Síndrome de Down em Engajamento Conjunto. 216 p. (Tese de Doutorado). PROLING/UFPB: João Pessoa, 2017. 
ÁVILA-NÓBREGA, P. V. o Estudo do Envelope Multimodal como uma Contribuição para a Aquisição da Linguagem. Curitiba: Editora Appris, 2018.

BATES, E.; O'CONNELL, B.; SHORE, C. Language and Communication in Infancy Development. New York: Wiley, 1987.

CAVALCANTE, M.C.B. Hologestos - produções linguísticas numa perspectiva multimodal. Revista Letras, Cutitiba, v.1/2, n.31, p.9-16, 2012.

COSTA FILHO, J. M. S. "Olá, Pocoyo!" A constituição da atenção conjunta infantil com o desenho animado. 2011. 141 f. Dissertação (Mestrado em Linguística) - Universidade Federal da Paraíba. João Pessoa, 2011.

DALLA DÉA, V.H.S.; BALDIN, A.D.; DALLA DÉA, V.P. Batista. Informações gerais sobre a síndrome de Down. In: DALLA DÉA, Vanessa Helena Santana; DUARTE, Edison (orgs.). Síndrome de Down: informações, caminhos, histórias de amor. São Paulo: Phorte, 2009. p. 23-42.

FREIRE, R.C.L.; et al. Aspectos neurodesenvolvimentais e relacionais do bebê com Síndrome de Down. Avances en Psicología Latinoamericana, Bogotá, Vol. 32, n. 2, p. 247-259, 2014.

GIL, A.C. Como elaborar projetos de pesquisa. 4.ed. Sâo Paulo: Atlas, 2002.

HAZEL, S.; MONTENSEN, K.; RASMUSSEN, G. Introduction: a body of resources - CA studies of social conduct. Journal of Pragmatics, v.65, p.1-9, 2014.

KENDON, A. Gesture: Visible Action as Utterance. Cambridge: Cambridge University Press, 2004.

LIMA, I. L. B. Interações multimodais na clínica de linguagem: a criança com Síndrome de Down. 137 f. Dissertação (Mestrado em Linguística) - PROLING/ UFPB: João Pessoa, 2016.

LIMA, I. L. B; CAVALCANTE, M. C. B. Desenvolvimento da linguagem na clínica fonoaudiológica em uma perspectiva multimodal. Revista do Gel, São Paulo, V. 12, n. 2, p. 89-111. 2015.

LIMA, I.L.B.; DELGADO, I.C.; CAVALCANTE, M.C.B. Desenvolvimento da linguagem na síndrome de Down: análise da literatura. Revista Distúrbios da Comunicação, v. 29, p. 354-364, 2017.

LIMA, I.L.B.; DELGADO, I.C.; CAVALCANTE, M.C.B. Relação entre a matriz linguística multimodal e a atenção conjunta de criança com síndrome de Down. Revista do GEL, v. 15, p. 85-99, 2018.

LIMA, K.A. Estudo comparativo do uso do apontar e sua relação com a produção vocal infantil, em cenas de atenção conjunta. 99 f. Dissertação (Mestrado em Linguística) - Universidade Federal da Paraíba. 2015.

MCNEILL, D. So you think gestures are nonverbal? Psychological Review, v. 92, n. 3, p. 350-371, 1985.

MCNEILL, D. Hand and mind: What gestures reveal about thought. Chicago: University of Chicago Press, 1992. 
V. 9 (3)

442-456 set-dez 2019

MIGUENS, S.G.A.M. Uma Teoria Fisicalista do Conteúdo e da Consciência: D. Dennett e os debates da filosofia da mente. 604 p. (Tese de Doutorado). Faculdade de Letras da Universidade do Porto, 2001.

PUESCHEL, S. M. Síndrome de Down: guia para pais e educadores. Campinas: Papirus, 2002.

SCHAFFER, R. H. The child's entry into a social word. London: Academic Press, 1984.

SOARES, M.L.C. Teorias de la intencionalidad, de Maria del Carmen Paredes Martín. Filosofia, Revista da Faculdade de Letras da Universidade do Porto. Vol. 25-26, 2008-2009. p. 191-197.

TOMASELLO, M. Origens culturais da aquisição do conhecimento humano. São Paulo: Martins Fontes, 2003. Tradução de Claudia Berliner.

TOMASELLO, M.; et al. Understanding and sharing intentions: The origins of cultural cognition. Behavioral and Brain Sciences, 2005: 28, 675-691. 